\title{
USING QUEUING SIMULATION MODEL IN PRODUCTION PROCESS INNOVATIONS
}

\author{
Vrecko, I. ; Kovac, J. ${ }^{* *}$; Rupnik, B. ${ }^{* * *} \&$ Gajsek, B. ${ }^{* * *}$ \\ *University of Maribor, Faculty of Economics and Business, Razlagova 14, 2000 Maribor, Slovenia \\ ${ }^{* *}$ University of Maribor, Faculty of Organizational Sciences, Kidriceva 55a, 4000 Kranj, Slovenia \\ **** University of Maribor, Faculty of Logistics, Mariborska 7, 3000 Celje, Slovenia \\ E-Mail: igor.vrecko@um.si,jure.kovac@fov.uni-mb.si, bojan.rupnik@um.si, brigita.gajsek@um.si
}

\begin{abstract}
Investment decision dilemmas were since late 60 's of previous century interesting for research from the perspective of financial dilemmas, while later, with arising uncertainty and dynamic of business environments, stochastic decisions problems needed more in-depth and complex considerations. High technology flexibility and multiple variation production process with significant losses related to resetting machine on one hand and great investment costs for new technology on the other hand, makes technology investment decisions in contemporary business environment multifarious. In this paper, we are presenting the case of optimizing investment decision dilemma in multiple variation production process. Using a discrete event simulation model we test two alternatives regarding the impact on predefined production indicators: 1) optimal grouping of the different products on an existing machine, 2) additional identical machine and optimal sorting of products between the existing and additional machine. In the paper, we determine indicators that should be monitored in investment decision dilemmas and design simulation model that can be used to calculate aforementioned indicators.
\end{abstract}

(Received in July 2018, accepted in October 2018. This paper was with the authors 1 month for 1 revision.)

Key Words: Production Process, Assembly, Optimisation, Innovations, Discrete Event Simulation Model

\section{INTRODUCTION}

In line with rapidly changing customer demands, ever-intensified market competition, growing product complexity and demanding legal requirements, there is a high demand on improved production efficiency, product quality, energy consumption and cost containment for manufacturing companies. Those have turned their attention from purely maximizing the capacity, the speed and the continuity of their production into enhancing product quality, decreasing production cost, reducing energy consumption and environment pollution [1].

In doing so, many industries have experienced a paradigm shift during the last 20 years from standardized, big scale manufacturing to low-volume manufacturing with flexible product characteristics. Companies had to, and still have to master the balance between economies of scale and the customers' demand for customized products. These developments constantly force manufacturing companies to adapt production processes to the latest technological trends and developments, but only few companies successfully manage the implementation of new process technologies in order to improve operational and business performance [2].

The manufacturing industry is currently under strong pressure to swiftly and easily adapt to changes [3]. Mass customization is becoming the ideology of today's manufacturing [4], [5]. This is coupled with dynamic requirements regarding lot sizes, product variants, lead times, and costs which emphasize the need for adaptable production systems. Simultaneous production of different products is a main requirement for economic usage and a better utilization of production equipment. Increased adaptability while keeping setup times to a minimum is the key feature of future manufacturing [6]. By being adaptable, intelligent, and 
versatile, future manufacturing systems can deal with the turbulent environment that they face [7].

One way by which manufacturing plants adapt to those environmental dynamics is the engagement in production process innovation. Companies that do not invest in innovation are entering into their future with a risk of losing their market share [8]. By speaking about production process innovation it doesn't mean only the use of new and advanced production technologies, which for example Lee et al. [9] and Sun [10] recognized as valuable weapon for manufacturing companies to address environmental challenges, but also intelligent reformulation of existing production processes leading to improved production output, productivity, machine utilization or customer satisfaction.

Various terms are used in the literature for technologies that are used within an industrial production unit and the activity of adopting them. The expressions range from [2]: production process innovation, manufacturing process innovation, manufacturing technology, manufacturing process technology to advanced manufacturing technology.

This paper is intended to demonstrate the usefulness of simulation models - in our case a discrete event simulation model, to provide better and more realistic data base for making decisions on organizing production, investing in increasing technological capacities, optimizing the implementation of the production process, and the like. The paper proceeds with incorporation of production process innovation into transaction cost theory and into resource-based theory, leading to the formation of simulation model for developing production process innovation decision bases, and finally, presenting the case for simulation.

\section{PRODUCTION PROCESS INNOVATIONS FROM TRANSACTION COST THEORY AND THE RESOURCE-BASED THEORY VIEW}

\subsection{Transaction cost theory view}

While research related to transaction cost theory is above all oriented to analysing processes governing exchange and adjustment in the economy, we can also use this theoretical framework to explain "correct" work distribution and specialization [11, 12].

The division of labour and specialization is the basis for increasing productivity. At the same time, it should be emphasized that both of them create demand for mutual coordination. Coordination is not carried out on its own but is related to certain targeted activities and elements. Costs arising as a result of the implementation of coordination activities are designated as transaction costs (or co-ordination costs).

The basic goal in the company is achieved through a joint task carried out by employees. We share a common task among employees according to various criteria. The degree of company's productivity depends to a large extent on the division of the joint task into individual partial tasks. The transaction cost theory helps us in interpreting the process of creating a division of labour, in particular from the point of view of the transaction costs that arise as a result of that division of labour. From this, it arises that transaction cost theory recommends carrying out a process of decomposition of a common task in such a way that it would, to the largest possible extent, form transactions (links) among performers of partial tasks (these could also be clients or suppliers) with lowest effort (cost) required for its completion [11, 13].

One of the key factors that influence the efficiency of the division of labour is the optimal transfer of the necessary knowledge to the performer of each partial task. We often refer to modern society as a knowledge society and knowledge is becoming one of the key factors for ensuring a competitive advantage for businesses. Creating an efficient process of transferring knowledge to partial tasks does not only reduce costs that are due to the lack of competence 
of the issuers of partial tasks, but also significantly contributes to the increase in productivity and a higher level of product or service quality. By means of an optimally organized process of knowledge transfer a suitable transfer of necessary knowledge between the knowledge operator and the performer of the single partial task can be assured.

Using simulation models therefore give operators necessary knowledge to optimise number of transactions and thus to manage production processes more efficiently and successfully.

\subsection{Resource-based theory view}

From a resource-based perspective, organizational effectiveness is defined as the ability of the organization, in either absolute or relative terms, to obtain scarce and valued resources and successfully integrate and manage them [14]. Questions about how to ensure long-term strategic advantages with individual resources and capabilities are put to the forefront. Many authors [15-18] use two basic assumptions about organizations resources and capabilities:

- that resources and capabilities can vary significantly across firms (the assumptions of organizations heterogeneity);

- that these differences can be stable (the assumptions of resource immobility) [19].

In the process of building long-term strategic advantages, the key task of managers is to analyse the existing potentials and define those areas in the company where the company can achieve long-term competitive advantages. In defining strategic competitive areas in the company, it is very important that we proceed from those existing competitive advantages of the company that the competition cannot imitate or are very difficult to imitate. Precisely imitation is the central element of a resource-based view of the organization. In the event that competing companies can develop or acquire similar resources as our own, then those abilities or resources cannot be the foundation of our sustainable competitive advantage.

Research within the framework of the resource-based theory has been and is still carried out in various directions [20]. One of the most recognizable directions is the creation of a link between resource-based theory with the theory on strategic actions in order to explain the achievement of strategic advantages. This direction explains how companies can connect very rare and specific sources and achieve sustainable competitive advantage through synergy [21]. The second direction of resource-based view emphasizes the company's ability to dynamically integrate the inputs [22].

Incorporating use of simulation models into production process optimisation can be interpreted through both views. On one hand, simulation and searching for best possible composition of production process has potential to create competitive advantage for an organization, and similar on the other hand, dynamic ability to best combine inputs through simulation optimisation lead to organization's competitive advantage.

\section{SIMULATION MODEL FOR DEVELOPING PRODUCTION PROCESS INNOVATION DECISION BASES}

Decisions in relation to production process innovation could be based on the observations from different levels of production systems. Neuhausen [23] expose four levels: factory level, segment level, line level and workplace level.

In our research we focused ourselves on the workplace level, where the actual service in the form of physical added value is performed under the combined resources of personnel, material and equipment and following a specific design principle. Through their number, their capabilities and their links with each other, the resources determine the operating range and the feasible processes of a workplace. 
The required lead time for manufacturing a product or commodity depends largely on the respective level of automation as well as the principle used in the machining processes. Normally a division into three basic process flow principles can be made [24]. The Process flow principle 1 follows a workplace in which the processes run in a sequence, i.e. consecutively; a product would first have to go through the processes P1 to P2 and then to P3 before the processing of another can begin. The Process flow principle 2 describes a workplace where parallel to the process $\mathrm{P} 1$, a product is simultaneously running through processes P2 and P3. Such a process flow is considered to be sequential-parallel and can, compared to Principle 1, shorten the processing time for each product. The limits of this are the utilization rates of the process-dependant resources. In Process flow principle 3 multiple processes at a workplace are running parallel in time. Compared with the other two principles, this is able to attain the shortest lead time, since the three separate processing operations can be carried out simultaneously on the same product. In the field of fully automated processing this requires a precise coordination of resources and processing methods.

In our research, we constructed a model for simulating influence of the $1^{\text {st }}$ degree manufacturing process innovation and of the $2^{\text {nd }}$ degree manufacturing process innovation based on the incorporation of advanced manufacturing technology on the selected internal factors (production output, productivity and machine utilization) and external factors (contract realization speed and flexibility) - see Fig. 1.

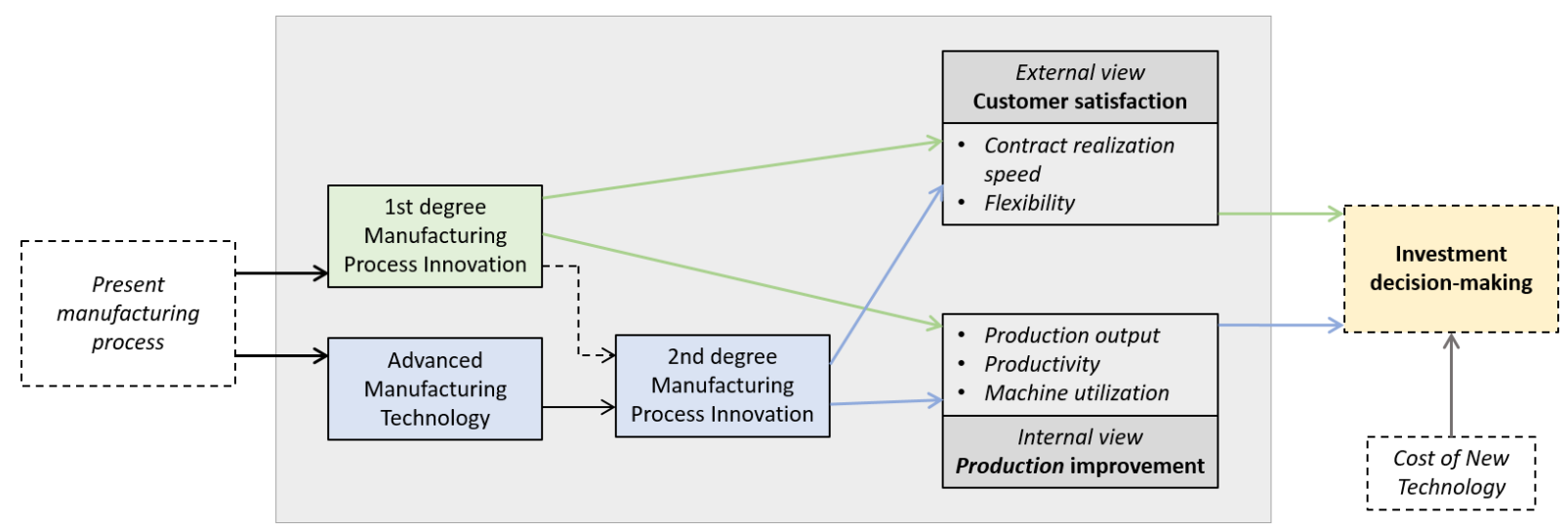

Figure 1: Technology investment decision-making model simulation.

Results of the simulation could be used in a many different ways; our interest was its usefulness on the investment decision dilemma.

\section{MODEL FOR DEVELOPING PRODUCTION PROCESS INNOVATION DECISION BASES}

\subsection{Presenting the case for simulation}

Manufacturing industry has become a leading industry during the economy development [25]. This gives impetus to research the effects of different investment opportunities that support the need for development.

Researched production facility produces approximately 600 pieces of door frames per day. The company is the largest manufacturer of interior doors in Slovenia, covers an area of ten thousand square meters, which has the function of production, warehousing and administration. We focus only on the part of the production hall where door frames are produced (see Fig. 2). 


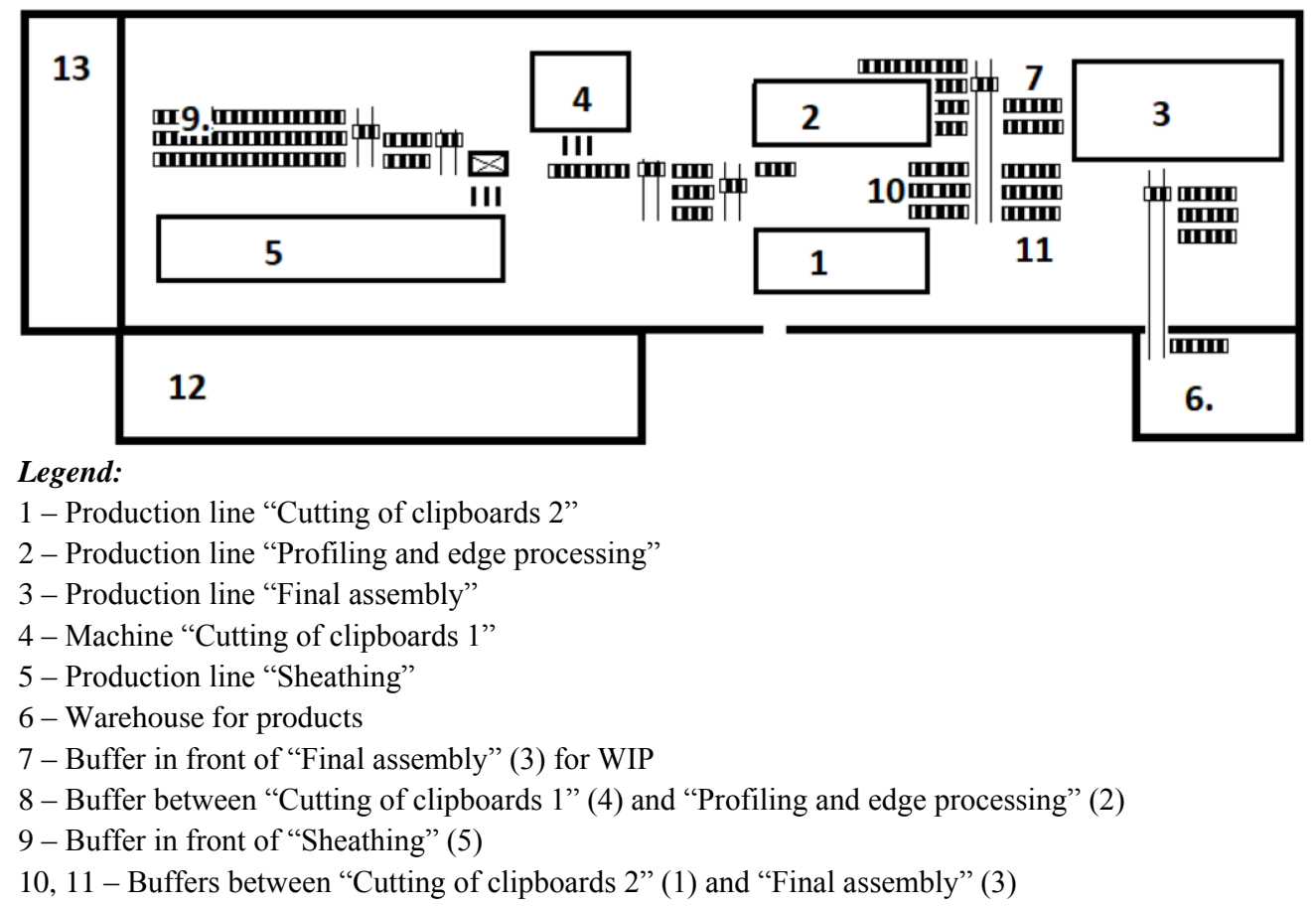

Figure 2: Door frames section layout.

Semi-finished/finished product's identification numbers define material flow through the production hall. Two major components of each frame are case profile and panel lining which assembled form closed door frame. Both components may be produced in two variants, with rounded or rectangular edges. Type of edge defines the path between production lines. Parts with rectangular edges have one operation less that rounded, which need sheathing of rounded edge.

Case profiles' production operations follow the predetermined sequence:

- Cutting of clipboards on machine "Cutting of clipboards 1", format circular saw with automatic or manual feeding of plates. Operation of the machine requires two workers. One makes use of the machine, and the other delivers wooden bases for semi products and clipboards for cutting on pallets from the warehouse with a forklift. Line can be served manually, one piece of clipboard after another, or automatically, four pieces of clipboard at the same time. Operator is depositing cut strips on a flat wooden base, placed on the roller conveyor. He also manually moves stacking along the conveyor, by pushing;

- Profiling and edge processing on production line "Profiling and edge processing". Operation of the line requires two workers. The first one sets up the line between different types, manually inserts semi products piece by piece from the stacking on roller conveyer on line's transport mechanism, controls quality on the end of the line and is responsible for adding of predefined colour and type of veneer strip. The second one is manually stripping profiled and processed case profiles on wooden bases on another roller conveyer placed on the end of the line. Case profiles with rectangular edges are after this phase ready for "Final assembly" and causally manually moved in buffer derived on five three-metre long roller conveyers placed one next to another along longitudinal track along which auxiliary staff pushes connecting trolley with integrated roller conveyor to relocate semi products. Case profiles with rounded edges are moved with forklift to production line "Sheathing";

- Sheathing the rounded edge on case profiles with rounded edges on production line 5 (see Fig. 2). The line operates under control of operator and his two co-workers. The first coworker is responsible for loading unsheathed semi-finished case profiles on automatic transport system at a beginning of the line. The operator sets up the line when the type of 
case profile is changed, is responsible for installation of veneer strip material in predefined colour and material, charges the tank with the adhesive, controls the quality of sheathed case profiles at the end of the line, bounds bundles of finished case profiles and hangs identification cards on them. The second co-worker shifts sheathed case profiles from the line on the palette, which is placed on the roller conveyor associated by connecting trolley on longitudinal track with two other four-metre long parallel roller conveyors intended for interfacial stocks. Case profiles with rounded edges are after this phase ready for final assembly on production line 3 (see Fig. 2). From buffer in front of production line 5 (9 in Fig. 2) they can be moved with forklift either to buffer in front of production line 3 ( 7 in Fig. 2) or first to warehouse (6 in Fig 2) and then to buffer (7 in Fig. 2).

Panel linings' production operations follow the predetermined sequence:

- Cutting of clipboards on production line 1 (see Fig. 2), which consist of several machines for automatic cutting and profiling of rounded edges. Operator sets up the line before next type of panel lining, controls the quality of panel linings and shifts them from the line on a flat wooden base, placed on the parallel roller conveyor. Panel linings with rectangular edges are after this phase ready for final assembly on production line 3 (see Fig. 2) and wait in buffer derived on five three-metre long roller conveyers placed one next to another along longitudinal track along which auxiliary staff pushes connecting trolley with integrated roller conveyor to relocate semi products. Panel lining with rounded edges are moved first with connecting trolley and then with forklift to production line 5 (see Fig. 2) for sheathing the rounded edges;

- Sheathing the rounded edge on panel linings on production line 5 (see Fig. 2). Process steps and workers' assignments are the same as for case profiles. Panel linings with rounded edges are after this phase ready for final assembly on production line 3 (see Fig. 2). From buffer in front of production line 5 (see Fig. 2) they can be moved with forklift either to buffer in front of production line 3 (11 in Fig. 2) or first to warehouse (6 in Fig. 2) and then to buffer in front of production line 3 (11 in Fig. 2).

Production line for final assembly consists of several machines with the function of cutting, drilling, gluing, turning, fittings assembly, insertion of the sealing strip and the like. Needed components are case profiles, panel linings, fittings, sealing strip and packaging material, which are temporarily stored around the line. Work on the line is scheduled according to the priority of orders, which generally comprise a smaller number of door frames, often only one piece. Ten workers are needed for operation of the line. Operator leads the group of workers, sets up and controls the line with help of computer. Two workers are in charge for loading the line with right case profiles and panel linings. Because of that, they regularly communicate with forklift driver and manually move stacking along longitudinal track by pushing connecting trolley with integrated roller conveyor between transverse roller conveyers aside. Another worker is inserting different fittings in dispensers, replacing sealing tapes and executes minor repairs of door frames. Five workers are packing door frames on the end of the line. In case of problems, they can stop the line for two minutes. After that time, the machine will automatically start to operate again. The last worker transfers packed door frame to warehouse manually with help of roller conveyer.

The production line 3 first shortens case profiles and panel linings if necessary. Every third piece can be cut in case of narrow doors to half (occurs one or two crosspiece of case profile/panel lining). In next step, crosspiece and two upright parts are joined. In next step, holder hinges and strike plates are installed, sealing tape is inserted. At the end of the line 3, parts of the door frame are visually controlled, fittings are packaged, instructions and mounting material are added. Workers insert everything into the cardboard and package. Packed door frames are loaded onto pallets, which are later manually pushed along roller conveyor into the warehouse of finished products. 
Door frames vary depending on the type of veneer, curved shape of edges, sealing tape colour, standard and fittings. All of this influences on the number and duration of setups on Final assembly (3 in Fig. 2). Rounded edges prolong production time because of transportation to production line 5 to execute sheathing. On production line 2 and production line 5 new type of veneer requires additional setup times because installation of veneer strip material in predefined colour and material. On all machines new type of veneer require change of material - pallet change.

\subsection{The simulation model}

Modelling of systems and processes before optimizing future solutions for production plans provides better choice and better optimization of solutions [26]. Various techniques have been widely used for analysis and optimization of production processes [27-30]. Among those, a variety of research is available regarding discrete event simulations, which have been used for acquiring knowledge about utilization and performance of the presented production system. Detty and Yingling [31] studied the quantified indicators for production benefits of introducing lean manufacturing. Božičković et al. [32] analysed the integration of simulation and lean tools into production systems, while Erikshammar et al. [33] considered the discrete event simulation for value stream mapping analysis. Zupan end Herakovic [34] studied management of production lines with discrete event simulation for production rate optimization. As discrete even simulation provides effective tools for analysing performance indicators we have applied the method for simulating the presented production system.

The main parameters observed for the simulation model were:

- $\lambda_{1}, \lambda_{4}, \lambda_{3}$ - arrival intensity of clipboards at (1) and (4) and at the assembly (3),

- $\mu_{i}$ - average service rates of machine/production line,

- $c_{i}$ - machine/production lines capacity,

- $S_{i}$ - average machine/production lines service time per piece,

- $\Delta S_{i}$ - average machine setup time required for changing product type.

The events listed by the method include the delivery of components to buffers, begin and end of process work on the machine/production lines, transfer from buffers between the machine/production lines, as well as downtimes due to maintenance or breaks. The process flow begins at either of the clipboard cutting machines. The cut panels at (4) are further transferred to profiling and edge processing (2), after which they are transferred to final assembly where are used along panels cut at (1). The other route transfers the components from profiling and edge processing to sheathing (5), from where they travel to the final assembly. The schematic in Fig. 3 shows the basic simulation model. The solid lines represent the direct material flow from one machine to the next, while the dashed lines represent transportation to the warehouse.

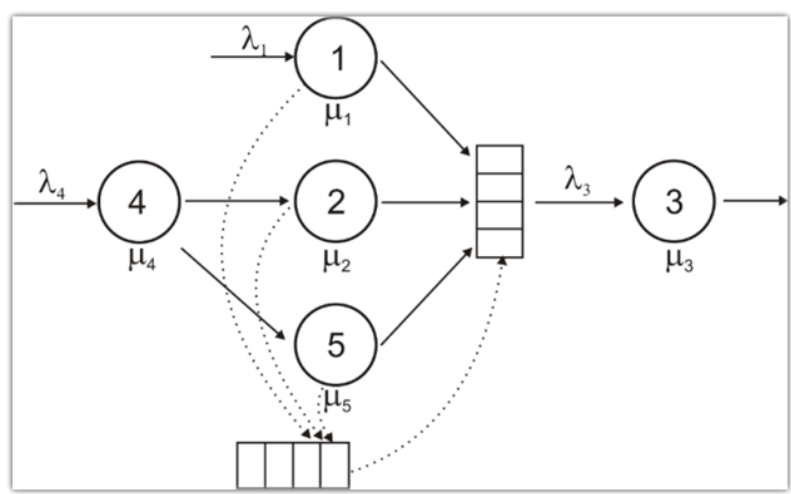

Figure 3: Simulation model of the production system. 
Except for panel cutting at (4) and final assembly (3), the components can be stored either in the warehouse for later use or the buffer in front of the assembly. Further details required in the model represent transportation times and schedules, and product types, which can influence both the routes as well as setup times at various machines. While straightforward production might allow for the analytic approach using queuing models, given the complexity of the system, discrete event simulation provides a more suitable method.

The simulation was done using the Flexsim simulation environment. Historical data of production orders as processed were taken as input. This ensured that the simulation came as near to the real situation as possible. The processing times of each machine was analysed in order to acquire the distribution of its service time. As the production allows arbitrary customization of the final product (from dimensions, profiles shapes, etc.) the machines need to be adapted for each individual product. This requires the setup times of an average slightly above 2.1 minutes per minor setup adjustment, and average 5.5 minutes per major setup adjustment on Profiling and edge processing (2). The changes are dependent on whether only the veneer type or the profile type as well. Otherwise, the production is constant at 6 seconds per batch, which consists of 8 items. Delays up to a minute can occur for loading additional material, in which case no additional setup is required. Average daily production at this stage is about 1500 pieces, where most are used for further processing at Final assembly (3), while a portion can be stored for later processing.

The final assembly performed on 3 (Fig. 2) requires handling multiple possible changes such as surface type, frame type, height setup, and lining thickness, which may all influence setup time. Final assembly (3) requires combining output of Cutting of clipboards 2 (3 items) and Profiling and edge processing ( 5 items). Setup time delays average from 2.7 minutes per minor change average 7.2 minutes per major type change. When processing single items, the mean processing time is 56 seconds, averaging between 550 and 650 finished products per day (varying between 2 and 3 shifts). The characteristics of individual machines of the production lines can be seen in Table I.

Table I: Machine properties of the simulated systems.

\begin{tabular}{|c|c|c|c|c|c|}
\hline $\begin{array}{c}\text { Machine } \\
(\text { see Fig. 2) }\end{array}$ & $\boldsymbol{c}_{\boldsymbol{i}}[\mathrm{pcs}]$ & $\begin{array}{c}\text { Minor adjustment } \\
\Delta S_{i}[\mathrm{~s}]\end{array}$ & $\begin{array}{c}\text { Major adjustment } \\
\Delta S_{i}[\mathrm{~s}]\end{array}$ & $\boldsymbol{S}_{\boldsymbol{i}}[\mathrm{s} / \mathrm{piece}]$ & $\boldsymbol{\mu}_{\boldsymbol{i}}[\mathrm{pcs} / \mathrm{h}]$ \\
\hline 1 & 8 & 40 & $/$ & 5.1 & 72.3 \\
\hline 2 & 8 & 126 & 250 & 6.0 & 110.7 \\
\hline 3 & 8 & 162 & 432 & 56.2 & 41.2 \\
\hline 4 & 1 & 33 & $/$ & 32.5 & 115.2 \\
\hline 5 & 10 & 100 & $/$ & 18.2 & 39.3 \\
\hline
\end{tabular}

The components produced prior to final assembly are stored either at the buffer in front of the assembly or in the warehouse in case of production overflow or scheduling requirements. During the shifts, the buffer is constantly provided with required components, which essentially means that the arrival intensity outstrips the service rate of machine 3 . The arrival intensity of the assembly could be expressed as the sum of the service rates of machines 1,2 , and 5 as well as transport from the warehouse, minus a minor time penalty for transfer:

$$
\lambda_{3}=\mu_{1}+\mu_{2}+\mu_{5}+\lambda_{w}
$$

By observing the average service rate values, it would appear that the system is stable, given that the service rate $\mu_{3}$ should cover the arrival intensity. However, when product orders that require major machine setups are processed this services rates can drop, which is mostly noticeable on final assembly, which is prone to a higher number required setup adjustments than on other machines. This leads to a greater inbound rate than processing rate of assembly:

$$
\frac{\lambda_{3}}{\mu_{3}}>1
$$


That identifies the assembly machine as the system bottleneck. When considering the reasons for the bottleneck, the higher production rate of other machines is not the only reason, but it is necessary to consider the input variety. As the production allows any desired combination, switching from one product to another often requires new machine setups, which may require shorter or longer delays, depending on the differences between consecutive production orders.

\subsection{The simulation results}

Along identifying bottlenecks, the aim of the simulation was to assess the machine utilization and find means to increase the production. The simulation run (see Table II) reveals a high utilization of final assembly, while the other machines reach expectedly lower values.

Table II: Machine utilization.

\begin{tabular}{|c|c|c|c|c|}
\hline Machine & $\boldsymbol{\rho}_{\text {total }}[\%]$ & $\boldsymbol{\rho}_{\text {work }}[\%]$ & $\boldsymbol{\rho}_{\text {setup }}[\%]$ & Output $[\mathrm{pcs} / \mathrm{h}]$ \\
\hline 1 & 67.3 & 34.0 & 33.3 & 232.0 \\
\hline 2 & 64.9 & 15.0 & 49.9 & 110.2 \\
\hline 3 & 99 & 27.8 & 71.2 & 42.3 \\
\hline 4 & 80.8 & 80.0 & 0.8 & 89.9 \\
\hline 5 & 77.2 & 70.8 & 6.4 & 290.3 \\
\hline
\end{tabular}

The utilization in Table II is an example of all machines working in unison, which is not always the case. As machines 1, 2 and 5 produce overflow, they are often not active in a full shift, while the final assembly is usually covered by a complete schedule. When considering the downtimes of those machines, their utilization would reach much lower values. High setup percentage of several machines reveals high susceptibility to product type changes. In order to resolve the cause of low production we propose the following scenarios to improve the production:

Scenario 1 - Adding another server for the bottleneck

Adding another machine for final assembly $\left(3^{*}\right)$ increases the production output by approximately $77 \%$. Further production increase would require reorganization of other production lines, as by this scenario the arrival intensity at the assembly reaches becomes stable:

$$
\frac{\lambda_{3}}{\mu_{3}}<1
$$

In this case, the new bottleneck becomes machine 2, which provides the majority of the input for the final assembly.

Scenario 2 - Minimizing setup times

Changes in material types (dimensions, profile type, lining, etc.) at various production stages require adjusting the individual machine setup. Some changes require only minor adjustments that require relatively short time a couple of minutes, while others may require a more time costly delay. Depending on the variety of products the solution to minimize delays for setup adjustments the solution is to reschedule the arrival of request types in the order that requires the fewest possible changes. Given a high variety in orders, this may not always be possible. However, merging product orders into batches of either same/similar dimensions or profile types often allows for switching from a required major setup adjustment to a minor one, which can yield several minutes of additional utilization.

For the purpose of the simulation, we have analysed the weekly production plan and grouped orders of similar product types that would require the least adjustment of various 
machines. Both the utilization of profiling as well as assembly improved by $12 \%$ and $9 \%$ respectively in favour of processing time instead of setup times. The overall production is increased to 47 door frames per hour.

Scenario 3 - Combining both solutions

As both solutions provide results, albeit with varying effect, the logical step is to simulate a model improved in accordance with both improvements. Using the same input plan as in scenario 2, while using the model in scenario 1, the utilization of Profiling and edge processing (2) can reach $80 \%$ (33\% effective work time), while Final assembly (3) utilization gets up to $90 \%$ (35\% effective). The hourly output at the final assembly is increased by 52 door frames per hour.

Table III: Rage process times and outputs for different simulation scenarios ( $3 *$ indicates an additional assembly machine).

\begin{tabular}{|c|c|c|c|c|c|c|c|c|}
\hline \multirow{3}{*}{ Machine } & \multicolumn{2}{|c|}{ Original } & \multicolumn{2}{c|}{ Scenario 1 } & \multicolumn{2}{c|}{ Scenario 2 } & \multicolumn{2}{c|}{ Scenario 3 } \\
\cline { 2 - 9 } & $\boldsymbol{\rho}[\%]$ & $\begin{array}{c}\text { Hourly } \\
\text { output }\end{array}$ & $\rho[\%]$ & $\begin{array}{c}\text { Hourly } \\
\text { output }\end{array}$ & $\rho[\%]$ & $\begin{array}{c}\text { Hourly } \\
\text { output }\end{array}$ & $\rho[\%]$ & $\begin{array}{c}\text { Hourly } \\
\text { output }\end{array}$ \\
\hline 1 & 67.3 & 232.0 & 67.3 & 232.0 & 67.9 & 231.0 & 67.3 & 232.7 \\
\hline 2 & 64.9 & 110.2 & 64.9 & 110.2 & 69.5 & 119.2 & 64.9 & 122.9 \\
\hline 3 & 99.0 & 42.3 & 91.2 & 37.5 & 99.0 & 47.3 & 91.2 & 44.5 \\
\hline $3^{*}$ & $/$ & $/$ & 91.2 & 37.5 & $/$ & $/$ & 91.2 & 44.6 \\
\hline 4 & 80.8 & 89.9 & 80.8 & 89.9 & 81.2 & 92.9 & 81.2 & 93.0 \\
\hline 5 & 77.2 & 290.3 & 77.2 & 290.3 & 77.2 & 294.4 & 77.2 & 295.1 \\
\hline
\end{tabular}

The comparison of all approaches can be seen in Table III. The simulation results reveal that the main problem of the production line is not in the machines and line setup itself, but the delays that are caused mainly by the high customization options of the finished products, which require time to adjust the machine setup. The simulation analysis reveals an increase of production output by resolving the apparent bottleneck. Optimization of the production schedule certainly appears a more cost friendly solution, however this might not always be feasible when production deadlines need to be upheld.

\section{CONCLUSION}

Considering the possible innovation approaches on the production productivity can certainly be improved. Given the possible scenarios the hourly output can be increased, which in turn decreases the lead time of production orders. While these also depend on the number of planned daily shifts the addition of another assembly machine presents a great production output increase. When addressing flexibility, it can be defined as a function of the level of product customization capacity and the production time. Flexibility can be increased by either increasing the level of customization or by decreasing the production time. As the presented case is based on full customization of the product, an emphasis on the production time can be given.

In the presented case the weekly of 5 work days the production reached $O u t_{\text {orig }}=2939$ pcs. In comparison, in the simulated scenario 1 the same amount could be produced in 3 work days (same number of shifts), meaning a part of the customers would have received their product 2 days earlier. When considering scenario 2, an s light increase in the daily production reached $O u t_{S 2}=3193$ pcs. Here the weekly production still lasted for 5 days, with a small number of the products being finished a day earlier. While a few customers might receive their product earlier, the rescheduling due to grouping of similar product types also postponed certain production orders to later processing, which might prove to be actually 
reducing the flexibility to a small degree. The last scenario $\left(O u t_{S 3}=5212 \mathrm{pcs}\right)$ is facing the same inconvenience, however the production boost by using another assembly machine reduces the overall production time enough that unsatisfactory cases are held by a minimum.

\section{ACKNOWLEDGEMENT}

This work was supported by University of Maribor, Faculty of Economics and Business and by Faculty of Logistics grants. The authors thank Slovenian Project Management Association for supporting paper preparation and the anonymous referees for their helpful comments and suggestions.

\section{REFERENCES}

[1] Chai, T. (2009). Plant-wide production processes: challenges on optimal control, Measurement and Control, Vol. 42, No. 7, 204-208, doi:10.1177/002029400904200703

[2] Schrettle, S. (2013). Managing manufacturing process innovation - New manufacturing technology adoption as a dynamic capability, PhD Dissertation, University of St. Gallen, School of Management, Economics, Law, Social Sciences and International Affairs, Difo-Druck GmbH, Bamberg

[3] Keddis, N.; Kainz, G.; Zoitl, A. (2014). Capability-based planning and scheduling for adaptable manufacturing systems, Proceedings of the 2014 IEEE Emerging Technology and Factory Automation (ETFA), 8 pages, doi:10.1109/ETFA.2014.7005213

[4] Nagel, R. N. (1991). $21^{\text {st }}$ Century Manufacturing Enterprise Strategy: An Industry-Led View, Report, Iacocca Institute, Lehigh University, Bethlehem

[5] Hu, S. J.; Zhu, X.; Wang, H.; Koren, Y. (2008). Product variety and manufacturing complexity in assembly systems and supply chains, CIRP Annals - Manufacturing Technology, Vol. 57, No. 1, 45-48, doi:10.1016/j.cirp.2008.03.138

[6] Koren, Y.; Heisel, U.; Jovane, F.; Moriwaki, T.; Pritschow, G.; Ulsoy, G.; Van Brussel, H. (1999). Reconfigurable manufacturing systems, CIRP Annals - Manufacturing Technology, Vol. 48, No. 2, 527-540, doi:10.1016/S0007-8506(07)63232-6

[7] Zor, S; Görlach, K.; Leymann, F. (2010). Using BPMN for modeling manufacturing processes, Proceedings of the $43^{\text {rd }}$ CIRP International Conference on Manufacturing Systems, 515-522

[8] Koren, R.; Prester, J.; Buchmeister, B.; Palčič, I. (2016). Do organisational innovations have impact on launching new products on the market?, Strojniski vestnik - Journal of Mechanical Engineering, Vol. 62, No. 6, 389-397, doi:10.5545/sv-jme.2016.3470

[9] Lee, J. Y.; Swink, M.; Pandejpong, T. (2011). The roles of worker expertise, information sharing quality, and psychological safety in manufacturing process innovation: an intellectual capital perspective, Production and Operations Management, Vol. 20, No. 4, 556-570, doi:10.1111/j.1937-5956.2010.01172.x

[10] Sun, H. (2000). Current and future patterns of using advanced manufacturing technologies, Technovation, Vol. 20, No. 11, 631-641, doi:10.1016/S0166-4972(00)00007-9

[11] Picot, A.; Dietl, H.; Franck, E. (1999). Organisation, Schäffer-Poeschel Verlag, Stuttgart

[12] Kieser, A., Walgenbach, P. (2010). Organisation, Schäffer-Poeschel Verlag, Stuttgart

[13] Jones, G. R.; Bouncken, R. B. (2008). Organisation: Theorie, Design und Wandel, $5^{\text {th }}$ edition, Pearson Studium, München

[14] Daft, R. L. (2001). Organization Theory and Design, South-Western College Publishing, Cincinnati

[15] Penrose, E. T. (1959). The Theory of the Growth of the Firm, John Wiley, New York

[16] Porter, M. E. (1980). Competitive strategy: Techniques for Analyzing Industries and Competitors, The Free Press, New York

[17] Rumelt, R. P. (1984). Towards a strategic theory of the firm, Lamb, R. B. (Ed.), Competitive Strategic Management, Prentice Hall, Englewood Cliffs, 556-570

[18] Wernerfelt, B. (1984). A resource-based view of the firm, Strategic Management Journal, Vol. 5, No. 2, 171-180, doi:10.1002/smj.4250050207

[19] Clegg, S. R.; Hardy, C. (Eds.) (1999). Studying Organization: Theory and Method, Sage Publication, London 
[20] Conner, K. R. (1991). A historical comparison of resource-based theory and five schools of thought within industrial organization economics: Do we have a new theory of the firm?, Journal of Management, Vol. 17, No. 1, 121-154, doi:10.1177/014920639101700109

[21] Barney, J. (1991). Firm resources and sustained competitive advantage, Journal of Management, Vol. 17, No. 1, 99-120, doi:10.1177/014920639101700108

[22] Teece, D. J.; Pisano, G.; Shuen, A. (1997). Dynamic capabilities and strategic management, Strategic Management Journal, Vol. 18, No. 7, 509-533, doi:10.1002/(SICI)10970266(199708)18:7<509::AID-SMJ882>3.0.CO;2-Z

[23] Neuhausen, J. (2001). Methodik zur Gestaltung modularer Produktionssysteme für Unternehmen der Serienproduktion, Dissertation Thesis, RWTH, Aachen

[24] Rogalski, S. (2011). Flexibility Measurement in Production Systems, Springer, Berlin

[25] Yu, B.; Wu, E.; Chen, C.; Yang, Y.; Yao, B. Z.; Lin, Q. (2017). A general approach to optimize disassembly sequence planning based on disassembly network: A case study from automotive industry, Advances in Production Engineering \& Management, Vol. 12, No. 4, 305-320, doi:10.14743/apem2017.4.260

[26] Gordić, B. (2017). Flexible optimization in the process of planning and production control, Technical Gazette, Vol. 24, No. 4, 1087-1094, doi:10.17559/TV-20160112132024

[27] He, S. H.; Li, X. D.; Wang, Y.; Zhu, H. H. (2017). An optimization model for automobile mixed assembly line under multiple constrains, International Journal of Simulation Modelling, Vol. 16, No. 4, 720-730, doi:10.2507/IJSIMM16(4)CO18

[28] Yang, B.: Chen, W.; Lin, C. (2017). The algorithm and simulation of multi-objective sequence and balancing problem for mixed mode assembly line, International Journal of Simulation Modelling, Vol. 16, No. 2, 357-367, doi:10.2507/IJSIMM16(2)CO10

[29] Wang, W. M.; Li, D. B.; He, F.; Tong, Y. F. (2018). Modelling and optimization for a selective assembly process of parts with non-normal distribution, International Journal of Simulation Modelling, Vol. 17, No. 1, 133-146, doi:10.2507/IJSIMM17(1)CO1

[30] Lv, Y.; Zhang, J.; Qin, W. (2017). A genetic regulatory network-based sequencing method for mixed-model assembly lines, Advances in Production Engineering \& Management, Vol. 12, No. 1, 62-74, doi:10.14743/apem2017.1.240

[31] Detty, R. B.; Yingling, J. C. (2000). Quantifying benefits of conversion to lean manufacturing with discrete event simulation: a case study, International Journal of Production Research, Vol. 38, No. 2, 429-445, doi:10.1080/002075400189509

[32] Božičković, R.; Radošević, M.; Ćosić, I.; Soković, M.; Rikalović, A. (2012). Integration of simulation and lean tools in effective production systems - case study, Strojniski vestnik Journal of Mechanical Engineering, Vol. 58, No. 11, 642-652, doi:10.5545/sv-jme.2012.687

[33] Erikshammar, J.; Lu, W.; Stehn, L.; Olofsson, T. (2013). Discrete event simulation enhanced value stream mapping: an industrialized construction case study, Lean Construction Journal, Vol. 2013, 47-65

[34] Zupan, H., Herakovic, N. (2015). Production line balancing with discrete event simulation: A case study, IFAC-PapersOnLine, Vol. 48, No. 3, 2305-2311, doi:10.1016/j.ifacol.2015.06.431 